\title{
Effects of aspirin on gastric prostaglandin E (PGE) and acid output in normal subjects ${ }^{1}$
}

\author{
C. CHILD, W. JUBIZ ${ }^{2}$, AND J. G. MOORE \\ From the Veterans Administration Hospital and the Divisions of Metabolism and Gastroenterology, Department \\ of Medicine, University of Utah College of Medicine, Salt Lake City, Utah, U.S.A.
}

SUMMARY Aspirin administration to normal subjects resulted in a reduction in gastric prostaglandin E (PGE) output. Both PGE concentration and gastric juice volume were decreased. Gastric acid output also decreased, although the difference was not statistically significant. An increased sensitivity of the PGE system to inhibition by aspirin at $11 \mathrm{pm}$, midnight, and 1 am was observed.

Prostaglandins are a group of long chain fatty acids found to be biologically active in a number of mammalian tissues, including the stomach. Inhibition of basal, pentagastrin, histamine or food stimulated gastric acid secretion has been demonstrated in animals after the administration of $\mathrm{PGE}_{1}$ (Wilson, 1974). In rats, gastric (Robert et al., 1968) and duodenal (Robert et al., 1971) ulcers have been prevented by $\mathrm{PGE}_{1}$ and $\mathrm{PGE}_{2}$ respectively. In humans, Classen et al. (1971) found that the intravenous infusion of $\mathrm{PGE}_{1}$ significantly inhibited gastric acid secretion. However, oral administration was associated with increased gastrointestinal motility without a reduction in gastric acid secretion (Horton et al., 1968). In addition, PGE is present in human gastric juice. In normal subjects a circadian rhythm in gastric PGE output with higher levels during the day than during the night has been reported from our laboratory. This PGE rhythm was in reciprocal phase relationship with the circadian gastric acid secretion in normal subjects. On the other hand, a disruption of PGE and acid rhythms and their phase relationship was found in patients with peptic ulcer (Tonnesen et al., 1974). In an attempt to understand the relationship between PGE and gastric acid secretion, we studied the effects of aspirin, a known prostaglandin inhibitor (Vane, 1971) on gastric PGE and acid secretion in normal subjects. Our findings are reported here.

'Supported by Veterans Administration Research funds and by Grant AM-5214 from NIH.

Address requests for reprints to: William Jubiz, M.D., Division of Metabolism, Department of Medicine, University of Utah College of Medicine, 50 North Medical Drive, Salt Lake City, Utah 84132, U.S.A.

Received for publication 14 October 1975

\section{Methods}

Gastric juice was collected hourly for 24 consecutive hours without (control period) and after aspirin administration in eight normal male subjects (age range 22-34 years, mean 25.2 years). Studies were begun at 8 am or $4 \mathrm{pm}$ after a 12 or 16 hour fast, respectively. Subjects were assigned at random to start with either the control or the aspirin period. During the latter, subjects received $3.3 \mathrm{~g}$ aspirin ( $1.1 \mathrm{~g}$ every eight hours) on each of five consecutive days before the 24 hour collection of gastric juice. The last oral aspirin dose was given eight hours before the collections of gastric juice were begun. Since oral ingestion of aspirin was not desirable while gastric collections were made, rectal suppositories containing $1.3 \mathrm{~g}$ aspirin were given every four hours. A sump nasogastric tube was positioned fluoroscopically in the gastric antrum. Gastric juice was obtained continuously by automatic interrupted suction and pooled at hourly intervals. During both collection periods each subject was studied under the same controlled conditions in a semi-isolated environment, receiving a continuous intravenous infusion of $3000 \mathrm{ml} 0.45 \%$ saline over 24 hours. Blood samples for salicylate levels were drawn every four hours.

For each hourly sample, the volume was measured and titratable acidity was determined with a $\mathrm{pH}$ meter by neutralization with $0 \cdot 1 \mathrm{~N} \mathrm{Na} \mathrm{OH}$. Results were expressed in $\mathrm{mEq} / \mathrm{l}$ or in $\mathrm{mEq} / \mathrm{h}$. The concentration of PGE was determined by radioimmunoassay as developed in our laboratory for plasma (Jubiz et al., 1972) and modified for gastric juice (Tonnesen et al., 1974). Results were expressed in $\mathrm{m} \mu \mathrm{g} / \mathrm{ml}$ or in $\mathrm{m} \mu \mathrm{g} /$ hour. Salicylate levels were measured by a colorimetric technique (Trinder, 1954). 


\begin{tabular}{|c|c|c|c|c|c|c|}
\hline & & $\begin{array}{l}\text { Volume } \\
(\mathrm{ml} / \mathrm{h})\end{array}$ & $\begin{array}{l}P G E \\
\text { concentration } \\
(m \mu g / m l)\end{array}$ & $\begin{array}{l}\text { PGE } \\
\text { output } \\
(m \mu g / h)\end{array}$ & $\begin{array}{l}\text { Acid } \\
\text { concentration } \\
(m E q / l)\end{array}$ & $\begin{array}{l}\text { Acid } \\
\text { output } \\
(m E q / h)\end{array}$ \\
\hline
\end{tabular}

Table Hourly gastric juice volume, PGE concentration and output, acid concentration and output in eight normal subjects before and after aspirin administration

* P values were calculated by $t$ test for correlated means based on chi squares (one tailed probability).
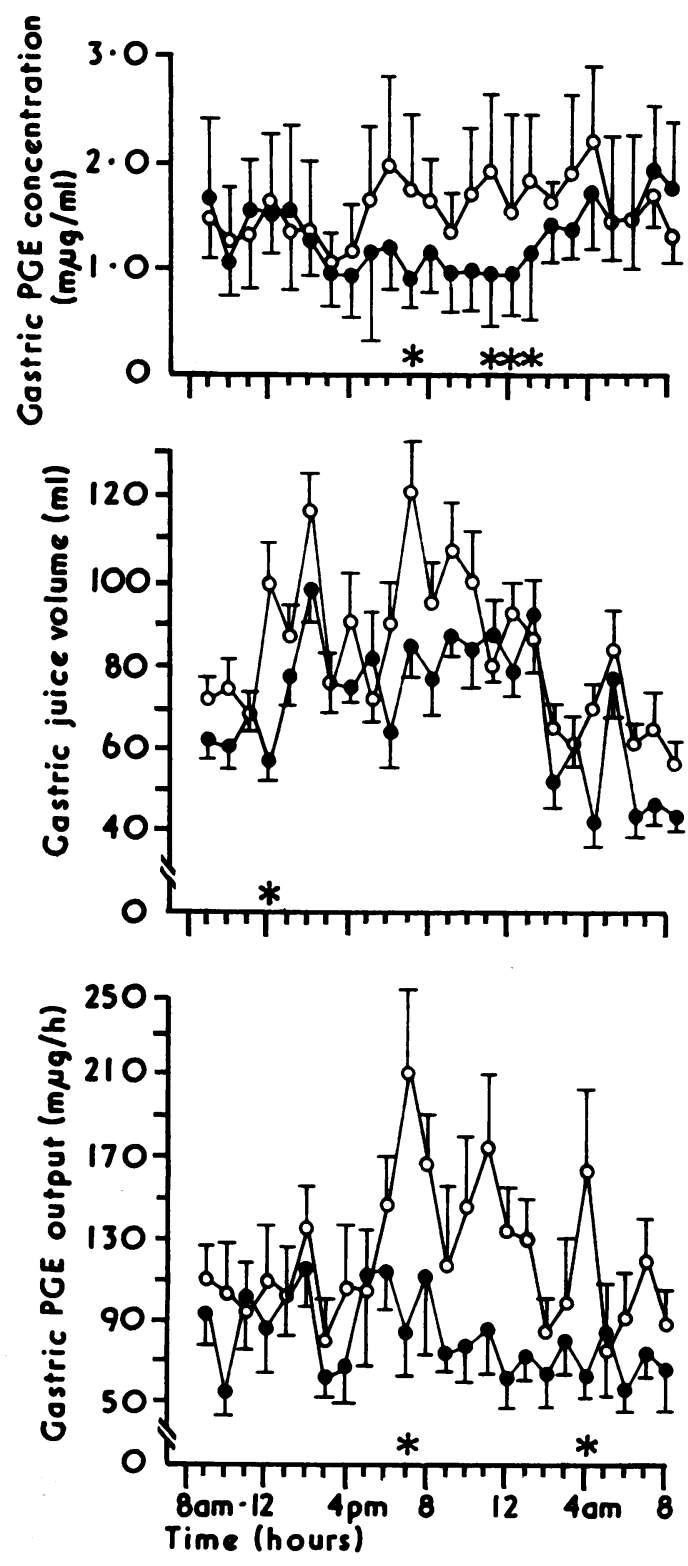

\section{Results}

Hourly gastric juice volume, concentration, and output for PGE and acid for the eight normal subjects during the 24 hour period are shown in the Table. After aspirin administration, a statistically significant reduction in PGE output, at the expense of PGE concentration and volume, was observed. A fall in acid concentration and output was also noted, although the difference was not statistically significant.

PGE concentration, gastric juice volume, and calculated PGE output before and after aspirin administration for each hour are shown in Fig. 1. Serum salicylate concentration was maintained between 20 and $30 \mathrm{mg} / \mathrm{dl}$ throughout the study. At these levels, we observed an obliteration of the circadian rhythm in PGE output primarily as the result of a fall in PGE concentration between $6 \mathrm{pm}$ and $4 \mathrm{am}$. Nonetheless, the differences were statistically significant $(P<0.05)$ only at $7,11,12 \mathrm{pm}$ and $1 \mathrm{am}$. Gastric juice volume also decreased but statistically significant differences were found only at noon. When the values after aspirin administration were expressed as a percentage of the corresponding control values, similar results were obtained (Fig. 2).

Results of gastric acid concentration and output and of gastric juice volume are presented in Fig. 3. In response to aspirin administration, gastric acid output did not change significantly.

\section{Discussion}

We have found an inhibition of the mean hourly gastric PGE output by aspirin in normal subjects resulting from a decrease in both PGE concentration and volume. As a result of this inhibition, the normal circadian rhythm in gastric PGE output was

Fig. 1 Gastric PGE concentration and output and gastric juice volume in eight normal subjects before $(O)$ and after aspirin administration (O). Values represent mean \pm SEM. ${ }^{*} \mathrm{P}<0.05$. 

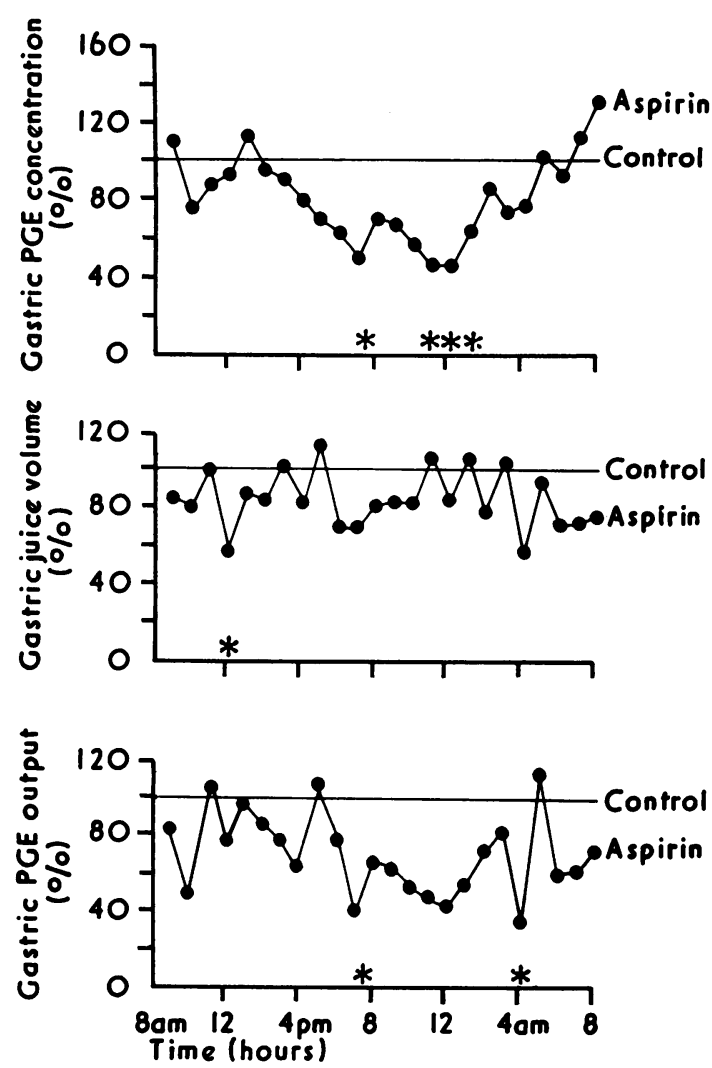

Fig. 2 Gastric PGE concentration and output and gastric juice volume in eight normal subjects after aspirin administration expressed as percent of control value (control mean is considered to be $100 \%$ for each hour). ${ }^{*} \mathrm{P}<0.05$.

abolished. Although the changes in PGE concentration and output appeared to have occurred mostly during the evening and early morning hours, a statistically significant difference was found only at four hours. Bennet et al. (1974) observed a fall in PGE output after indomethacin administration that was attributed to a decrease in volume rather than concentration. In our study with aspirin, we also observed a decrease in volume but an even greater decrease in PGE concentration. The reduction in prostaglandin output suggests that aspirin inhibits prostaglandin synthesis, presumably by inhibiting the enzyme prostaglandin synthetase that is believed to be present in the stomach fundus (Pace-Asciak, 1972). An increased sensitivity of the PGE system to the inhibitory effects of aspirin, unrelated to the time of administration, was observed around midnight. The significance of this finding is not apparent at the present time.
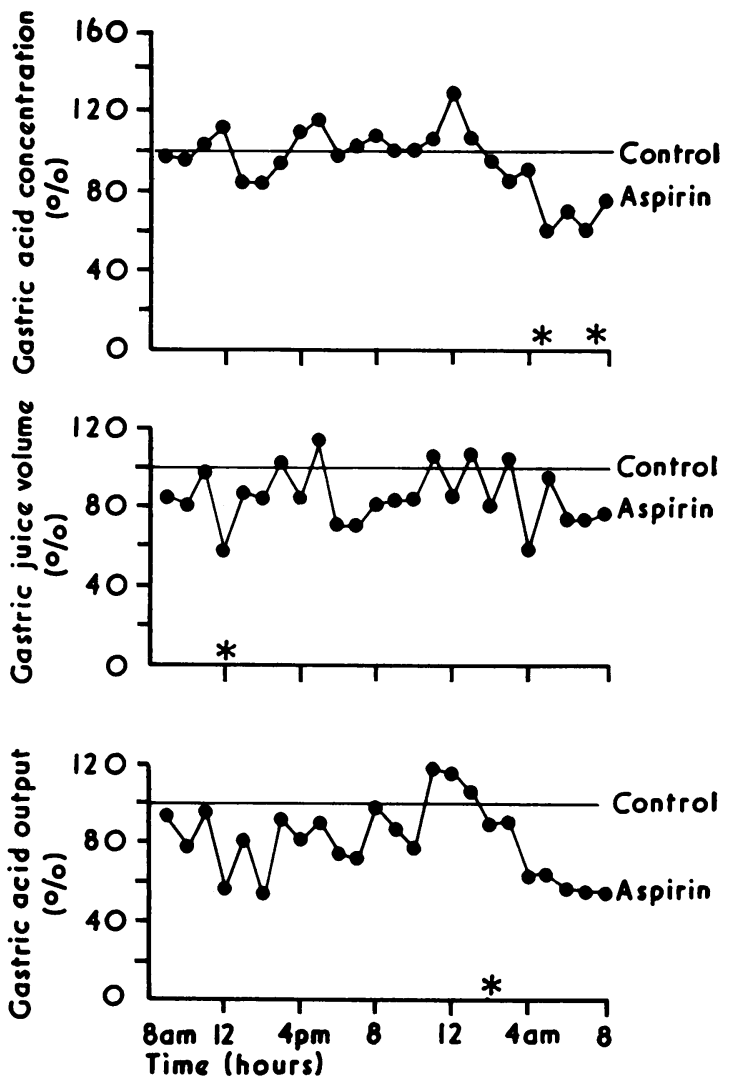

Fig. 3 Gastric acid concentration and output and gastric juice volume in eight normal subjects after aspirin administration expressed as percent of control value (control mean is considered to be $100 \%$ for each hour). ${ }^{*} \mathrm{P}<0.05$.

The authors wish to express their gratitude to Jose López for his assistance in the collection of the gastric juice samples and to Cherrinda Gardner for secretarial help.

\section{References}

Bennett, A., Stamford, I. F., Unger, W. G. (1973). Prostaglandin $\mathrm{E}_{2}$ and gastric acid secretion in man. Journal of Physiology, 229, 349-360.

Classen, M., Koch, H., Bickhardt, J., Topf, G., and Demling, L. (1971). The effect of prostaglandin $E_{1}$ on the pentagastrin-stimulated gastric secretion in man. Digestion, 4, 333-344.

Horton, E. W., Main, I. H. M., Thompson, C. J., and Wright, P. M. (1968). Effect of orally administered prostaglandin $E_{1}$ on gastric secretion and gastro-intestinal motility in man. Gut, 9, 655-658.

Jubiz, W., Frailey, J., Child, C., and Bartholomew, K. (1972). Physiologic role of prostaglandins of the E(PGE), F(PGF) and $A B(P G A B)$ groups. Estimation by radioimmunoassay in unextracted human plasma. Prostaglandin, 2, 471-489. 
Pace-Asciak, C. (1972). Prostaglandin synthetase activity in the rat stomach fundus. Biochimica et Biophysica Acta, 280, 161-171.

Robert, A., Nezamis, J. E., and Phillips, J. P. (1968). Effect of prostaglandin $E_{1}$ on gastric secretion and ulcer formation in the rat. Gastroenterology, 55, 481-487.

Robert, A., Stowe, D. F., and Nezamis, J. E. (1971). Prevention of duodenal ulcers by administration of prostaglandin $\mathrm{E}_{2}\left(\mathrm{PGE}_{2}\right)$. Scandinavian Journal of Gastroenterology, 6 , 303-305.

Tonnesen, M. G., Jubiz, W., Moore, J. G., and Frailey, J.
(1974). Circadian variation of prostaglandin E(PGE) production in human gastric juice. American Journal of Digestive Diseases, 19, 644-648.

Trinder, P. (1954). Rapid determination of salicylate in biological fluids. Biochemical Journal, 57, 301-303.

Vane, J. R. (1971). Inhibition of prostaglandin synthesis as a mechanism of action for aspirin-like drugs. Nature (New Biology), 231, 232-235.

Wilson, D. E. (1974). Prostaglandins: their actions on the gastro-intestinal tract. Archives of Internal Medicine, 133, 112-118.

\section{The December 1975 Issue}

\section{THE DECEMBER 1975 ISSUE CONTAINS THE FOLLOWING PAPERS}

Kinetics of bile acid metabolism in experimental blind loop syndrome STEFFEN BENDER, HOLGER SAUER, AND, DIETER HOFFMANN

Gallstones after ileostomy and ileal resection G. L. HILL, W. S. J. MAIR, AND J. C. GOLIGHER

Gallbladder function, cholesterol stones, and bile composition G. ANTSAKLIS, M. R. LEWIN, D. JUNE SUTOR, A. G. A. COWIE, AND C. G. CLARK

Progressive intrahepatic cholestasis (Byler's disease): case report R. DE VOS, C. DE WOLF-PEETERS, V. DESMET, E. EGGERMONT, AND K. VAN ACKER

Effect of vagotomy on secretin release in man A. $S$. WARD AND S. R. BLOOM

Postprandial osmotic and fluid changes in the upper jejunum after truncal vagotomy and drainage in man J. G. TEMPLE, ALMA BIRCH, AND R. SHIELDS

Post-prandial changes in $\mathrm{pH}$ and electrolyte concentration, in the upper jejunum after truncal vagotomy and drainage in man J. G. TEMPLE, ALMA BIRCH, AND R. SHIELDS

Alcohol tolerance after proximal gastric vagotomy A. FRASER MOODIE, C. M. S. ROYSTON, AND J. SPENCER

Migration inhibition with various cell fractions in human colorectal cancer P. R. ARMITSTEAD AND G. GOWLAND
Glucagon and the colon I. TAYLOR, H. L. DUTHIE, D. C. CUMBERLAND, AND R. SMALLWOOD

Mucosal lesions in the human small intestine in shock U. HAGLUND, L. HULTÉN, C. ÅHREN, AND O. LUNDGREN

Serum lysozyme in inflammatory bowel disease M. W. DRONFIELD AND M. J. S. LANGMAN

Vitamin $\mathbf{B}_{12}$ absorption - a study of intraluminal events in control subjects and patients with tropical sprue C. R. KAPADIA, P. BHAT, E. JACOB, AND S. J. BAKER

External pancreatic secretion after bombesin infusion in man NICOLA BASSO, SERGIO GIRI, GIOVANNA IMPROTA, EMANUELE LEZOCHE, PIETRO MELCHIORRI, MASSIMO PERCOCO, AND VINCENZO SPERANZA

Effect of secretin on release of heterogeneous forms of gastrin EUGENE STRAUS, ADRIAN J. GREENSTEIN, AND ROSALYN S. YALOW

Does human pancreas contain salivary-type isoamylase? JUNNOSUKE SHIMAMURA, LOUIS FRIDHANDLER, AND J. EDWARD BERK

Notes and activities

Notes on books

Copies are still available and may be obtained from the PUBLISHING MANAGER, BRITISH MEDICAL ASSOCIATION, TAVISTOCK SQUARE, LONDON, WC1H 9JR, price $£ 2 \cdot 00$, including postage 